\title{
Some New Insights into Monetary Transmission Mechanism in Bulgaria
}

\author{
Alexandru Minea \\ University of Auvergne \\ Christophe Rault \\ University of Orléans
}

\begin{abstract}
The presence of a Currency Board (CB) monetary system in Bulgaria is a key factor in assessing monetary policy transmission. Using a generalized impulse response analysis, we propose evidence based on the estimation of VAR models supporting the endogeneity of main Bulgarian monetary aggregates, in response to shocks on the ECB interest rate. These results, together with the analysis of the behavior of real variables, shed a new perspective on the CB functioning of Bulgaria.
\end{abstract}

- JEL Classification : C52, E42, E52

- Key Words: currency board, monetary policy, VAR, Bulgaria, GIRF

\section{Introduction}

Understanding monetary policy is without doubt a traditional yet very active research field in economics. Empirical and theoretical studies address the problem of monetary policy transmission, by trying to describe the different channels

\footnotetext{
*Alexandru Minea(Corresponding author): CERDI (University of Auvergne), Boulevard Francois Mitterrand, B.P. 320,63009 Clermont-Ferrand Cedex 1, France, e-mail: alexandru.minea@uclermont1.fr, webpage: http://minea.alexandru.googlepages.com, Christophe Rault: LEO (University of Orléans), CNRS, UMR 6221, Rue de Blois, B.P. 6739, 45067 Orléans Cedex 2, France, CESifo and Research Fellow, BEM (Bordeaux Management School), e-mail: christophe.rault@univ-orleans.fr, webpage: http://chrault3.free.fr/ @2009-Center for International Economics, Sejong Institution, Sejong University, All Rights Reserved.
} 
through which policy-makers' decisions on monetary policy instruments propagate in the economy, as well as their impact on key economic variables (see, inter alii the classical contributions from Sims, 1992, or Bernanke and Mihov, 1998, or the survey of Christiano et al., 2000). We denote by monetary policy instruments different monetary variables, that a policy-maker can control and change in a discretionary way. For instance, the European Central Bank (ECB) controls and changes the refinancing interest rate, in order to (hope to) put the economy on the desired path. ${ }^{1}$

As Taylor (1995) emphasized, traditional IS-LM Keynesian-based macroeconomic theory in a country with complete autonomy of monetary policy suggests that a tightened monetary policy (i.e. a discretionary raise in the interest rate or a decrease in money supply growth rate), should limit price growth (lower inflation), negatively affect output growth (via the negative effect on investment, thus on aggregate demand) and lead to an appreciation of the exchange rate (as higher interest rates increase domestic asset demand relatively to the demand in the rest-of-the-world assets).

However, little is known about monetary policy transmission in countries with a Currency Board (CB) monetary system. In a CB, domestic currency is anchored to another country's currency by a fixed exchange rate, which is settled by law. In an orthodox (first generation) $\mathrm{CB}$, monetary authorities control neither the interest rate nor the money supply. Consequently, the aim of our paper is to develop the existing literature by providing an analysis of monetary policy transmission under the CB monetary system of Bulgaria. ${ }^{2}$

Since, under a $\mathrm{CB}$, domestic monetary variables are not controlled by the domestic monetary authorities (for Bulgaria, the Bulgarian National Bank $\mathrm{BNB}^{3}$ ), our first objective is to find an appropriate exogenous monetary instrument. ${ }^{4}$ After considering five potential candidates, we select the ECB interest

${ }^{1}$ For example, the ECB might raise the interest rate whenever anticipated inflation is too high, to induce a downward revision of these expectations. While actual evidence considers the interest rate as the main monetary instrument, monetary aggregates have fulfilled this task in the past (see Peersman and Smets, 2001).

${ }^{2}$ Among other countries that used or use CB monetary system, we recall Argentina, Bosnia or Hong Kong. Section two develops the discussion over the characteristics of a Currency Board.

${ }^{3}$ This is partially true for the second-generation CB in Bulgaria, since the BNB can perform some limited form of discretionary monetary policy. Section two discusses in detail this point.

${ }^{4}$ In the following, calling a variable "exogenous" signifies that it can be changed through a discretionary decision. For example, the ECB interest rate is exogenous, in the way that it may be discretionary changed by the $\mathrm{ECB}$, while variations in the Bulgarian interest rate are endogenous, in the way that they are determined exclusively by the market responses and not by the BNB (given the presence of a CB in Bulgaria). 
rate as the main source of exogenous monetary shocks affecting the Bulgarian economy (recall that the Bulgarian currency (LEV) was initially anchored to the $\mathrm{DM}$ and currently against the EURO, $1 \mathrm{EUR}=1.95583 \mathrm{BGN}^{5}$ ). We examine the transmission of changes in the ECB interest rate to domestic monetary (interest rate, money, prices) and real(output, consumption, investment, public spending, trade) variables. In doing so, our paper develops the existing literature in three ways.

First, we investigate for the first time (to the best of our knowledge) monetary policy transmission in Bulgaria, while the usual analysis on Bulgaria focuses on the 1997 crisis (see, for example, Berlemann and Nenovsky, 2004). Therefore, our study develops the monetary policy transmission evidence for countries with monetary systems close to Bulgaria (see Lättemäe, 2003, for Estonia, Vetlov, 2003, for Lithuania, and Babich, 2001, for Latvia).

Second, in contrast to studies that build on Structural VARs (SVARs), we use a different approach, based on Generalized Impulse Response Functions (GIRFs) developed by Pesaran and Shin (1998). The reason of our choice is double. First, to achieve identification in a SVAR, one must implement economic-based constraints, or, if we restrict to recursive SVARs, this means that generally, the ordering of variables crucially affects results. While much is known about monetary shock transmission in countries with autonomous monetary policy, the evidence about the order in which shocks propagate in countries under a CB is still very crude (recall that domestic monetary variables are endogenous in a CB). Since variables' responses in a SVAR are ordering-dependent, this sheds a serious drawback on this method when transmission mechanism is unknown in advance, which may be the case in a CB monetary system. This leads us to the second reason explaining our choice, since GIRFs are invariant to the ordering of variables in the VAR (see the well-known critique of Lütkepohl, 1991) or, to put it differently, the use of GIRF prevents us from imposing constraints about which we have little information. ${ }^{6}$

Finally, our paper provides an original explanation for our results, based on the endogeneity of monetary aggregates, which is an essential fact in a CB monetary system, as the one in Bulgaria. Precisely, following an ECB shock, domestic monetary variable responses are rather irregular (cyclical) and differ from

\footnotetext{
${ }^{5}$ To define the exchange rate against the anchor, Hanke (2002) reports that Bulgarian authorities first announced the introduction of a CB, then allowed for a short floating period and finally defined the fixed exchange rate as being equal to the one at the end of the floating period.

${ }^{6}$ However, for robustness issues, we propose a comparison of our results with those obtained in a SVAR.
} 
traditional responses in countries with an autonomous monetary policy. In particular, the Bulgarian interest rate follows the ECB interest rate in the mediumlong-run only, while the two interest rates are disconnected in the short-run, and money supply presents a cyclical adjustment. In this perspective, the behavior of domestic monetary variables may be qualified as endogenous, in the sense that they are driven by market behavior rather than institutional reaction, which may reproduce key facts on the $\mathrm{CB}$ functioning. ${ }^{7}$ Notice that this interpretation is supported by output response: since, under a $\mathrm{CB}$, the evolution of monetary variables is not anchored to some discretionary behavior of the National Bank, real economy reacts to ECB rate changes with a delay (close to three quarters). Since our model does not impose any constraint on output behavior, this result may reproduce the incapacity or undesirability of agents influencing real economy to formulate short-run decisions, in the absence of autonomous domestic monetary guidance. ${ }^{8}$

The rest of the paper is organized as follows. In section II we present the CB monetary system in Bulgaria and discuss the choice of an exogenous monetary instrument. Section III describes the data and considers some methodological issues, while section IV reports our main results and several robustness tests, and section V concludes.

\section{An Overview of the Bulgarian Monetary System and Monetary Policy}

\section{A. The Bulgarian Crisis and General Considerations on the CBs}

The evolution of the Bulgarian economy between the fall of the communist wall and 1996 may be characterized by high instability. With the process of privatization evolving at a very slow pace (20 per cent of assets being privatized before 1997) and political pressure on banks to subsidies loss-generating state-owned companies, the financial system became increasingly fragile and accumulated enormous amounts of "bad" credits. This "bad" dynamic in the transition process

\footnotetext{
${ }^{7}$ To put it differently, for example, the Bulgarian interest rate is determined by the money market and not by some rule (or behavior, or discretionary decision) of the BNB. If this was the case, one might have expected the Bulgarian interest rate to closely (including in the short-run) follow the path of the ECB interest rate.

${ }^{8}$ In a country with autonomous monetary policy, agents' expectations on monetary policy are driven by discretionary decisions of the National Bank. Lacking this information may involve "time-to-build" behavior of agents, i.e. their need to acquire future information about monetary variables' evolution, before taking decisions affecting the real economy.
} 
was accompanied by deterioration in monetary conditions. To overcome the reduction of foreign currency reserves to some 500 million USD, the monetary authorities proceeded to subsequent exchange rate devaluations in 1994-1995. These devaluations had only some temporary effect and reserves dropped again to some critical threshold in the middle of 1996, leading to the start of the crisis. During 1997, the exchange rate, following several devaluations superior to 50 per cent, has suffered an impressive devaluation of 230 per cent with respect to USD, reserves dropped to a historical minimum of 300 million USD, monthly inflation and the base interest rate rose up to 250 per cent, real activity shrank by 7 per cent and unemployment climbed to 14 per cent (for more details see Berlemann and Nenovsky, 2004).

Following this severe twin (currency and banking - 14 commercial banks went bankrupt, representing almost one third of the number of banks and $25 \%$ of the consolidated bank balance sheet) crisis, there was need for a new monetary system. This new system should answer to two requirements: it should stop the crisis and provide long-term stability. Since an inflation-targeting system is based on reputation and thus powerless in the short-run, Bulgaria adopted on 17 February, 1997 the decision to introduce a Currency Board (CB) monetary system, which was made effective by the new political party (that won April election) starting 1 July, $1997 .{ }^{9}$ Notice that this decision represents the most profound institutional change of the BNB, since its establishment in 1879 and that it has been motivated by several factors. From a historical point of view, Bulgaria adopted a Gold exchange Standard (GS) regime (in which the LEV was fixed against gold) in 1928, and CBs are often compared with a GS regime. ${ }^{10}$ Furthermore, ideas on the introduction of a CB in Bulgaria were circulating since the beginning of the 1990s, as for example Hanke and Schuler (1991) who suggested the adoption of a CB to support the LEV. Finally, as emphasized by one of the architects of the Bulgarian CB (see Hanke, 2007), the introduction of a CB in Bulgaria was also supported by the IMF.

\footnotetext{
${ }^{9}$ Besides, a CB strictly restricts the possibility of a future monetization of the public debt, which rose to three digits (in per cent of GDP) in 1996.

${ }^{10}$ In a comprehensive comparison, Desquilbet and Nenovsky (2004) summarize six striking similarities between CB and GS (p.2): (i) a high level of credibility and confidence, (ii) tools for integrating national economies into the world economy, (iii) the presence of an automated mechanism, linking money demand, money supply and the balance of payments, (iv) impose external limitations to the domestic economy, (v) are relatively rigid (minimum discretion) and restrictive, and (vi) were often used as stabilizing measures after the period of financial crisis and hyperinflation.
} 
In adopting a CB, Bulgaria joined Estonia and Lithuania who introduced CBs anchored on the German Mark and USD in 1992 and 1994 respectively, and to some extent Latvia, where the national currency is in a fixed peg with the SDR (a basket of currencies).

A Currency Board is an extreme institution of monetary regime (Nenovsky and Rizopoulos, 2004, p.909) and it was implemented for the first time in Mauritius, starting 1849. According to Schuler (1992), the use of CB monetary systems reached its peak in the mid 1950s and then continuously declined due to several reasons, among which nationalist sentiments and the desire of an autonomous monetary policy. Even if currently only few countries still use CBs, they continued to be studied since they may produce interesting insights about related forms of monetary organization (i.e. dollarization or monetary unions).

To summarize, an orthodox $C B$ arrangement is an exchange rate arrangement whereby the monetary authority stands ready to exchange local currency for another (anchor) currency at a fixed exchange rate without any quantitative limits (Pikkani, 2000, p.6). To supply foreign currency on demand, a CB implies a 100 per cent backing of emitted domestic currency with foreign exchange reserves. Schuler (1992, p.2) adds that its [CB] reserve ratio is fixed at 100 percent or slightly more of its notes and coins in circulation, ${ }^{11}$ as set by low. [...] The currency board has no discretion in monetary policy; market forces alone determine the quantity of notes and coins in circulation. In turn, full backing of the domestic base money and full convertibility at a fixed exchange rate assures a totally endogenous base money supply, ${ }^{12}$ since any excess liquidity is automatically sterilized. Any ceteris paribus change in money demand will induce changes in base money and the corresponding changes in foreign exchange reserves, as base money follow the dynamics of the balance of payments. ${ }^{13}$ Consequently, as Lättemäe (2003) explains, in a joint study on the $\mathrm{CB}$ systems of Estonia and Lithuania, in a (orthodox) $\mathrm{CB}$ there is no active monetary policy.

\section{B. The Bulgarian CB and the Identification of Monetary Shocks}

One important feature that the recent related literature stresses (see Hanke, 2002,

\footnotetext{
${ }^{11}$ Under this condition authorities cannot run out of reserves.

${ }^{12}$ Niggle (1991) discusses the different theories that deal with the money stock endogeneity.

${ }^{13}$ This is the so-called "automatic mechanism" (AM) of a CB (for more details, see Hanke and Sekerke, 2003). Nenovksy et al. (2001) recall that the merely definition of the AM is still subjected to controversies in the literature.
} 
or Nenovsky and Hristov, 2002) is the difference between first-generation or "orthodox" CBs (typically in the colonial system) and nowadays CBs (second generation or quasi-CBs). Let us discuss the features of the Bulgarian $\mathrm{CB}$ in the light of this difference. ${ }^{14}$

Several characteristics of the CB in Bulgaria are inherited from orthodox CBs. For example, the existence of a fixed exchange rate between the LEV and the anchor (EURO) or the fact that reserves must be at least at 100 per cent, are guaranteed by law. In particular, this differentiates a CB from a monetary system where the domestic currency is pegged against other currencies (for example, Latvia). On the other side, the CB in Bulgaria presents several second-generation $\mathrm{CB}$ characteristics. In particular, as emphasized below, the BNB may conduct some restricted form of monetary policy (contrary to orthodox CBs which completely exclude it). ${ }^{15}$

To sum up, on the one hand, neither monetary aggregates, nor the domestic interest rate can be considered as pure monetary instruments and used accordingly. In terms of our future modeling, this implies that studying exogenous changes in either domestic interest rate or money aggregates, which is econometrically computable, has limited interpretation (see, for example, Hanke and Schuler, 1994). On the other hand, since we aim at studying exogenous monetary shock transmission on the Bulgarian economy, we should take into account the secondgeneration characteristics of the Bulgarian $\mathrm{CB}$, in order to properly define shocks that can be considered as exogenous (i.e. decided in a discretionary way by the BNB or by an external monetary authority - the ECB, for example).

All together, we have managed to identify five potential exogenous shocks. The first and most important concerns changes in the ECB interest rate. Since the Bulgarian currency is pegged against the EURO, changes in the ECB interest rate should transit to the Bulgarian domestic interest rate and further to all key macroeconomic variables.

Second, notice that pegging against an anchor does not completely eliminate fluctuations, since the anchor can float against other trade partners' currencies. An interesting example is Lithuania, where from 2002 on, the anchor was fixed against

\footnotetext{
${ }^{14}$ Miller (1999) and Nenovsky and Hristov (2002) offer more insights about the CB in Bulgaria, while Hanke (2007) outlines the performances of the Bulgarian economy before and after the introduction of the $\mathrm{CB}$.

${ }^{15}$ There exist few theoretical models explaining the second-generation $\mathrm{CB}$ functioning, including Pikkani (2000), Desquilbet and Nenovsky (2003) or Blessing (2007). Hanke (2002) considers the Bulgarian CB as the "least orthodox" among the existing CBs.
} 
the EURO, while an important share of trade is done with Russia (although the EU is the most important trade partner). In this case, studying the effect of changes in the currency of an important trade partner (different from the "anchor currency" partner) might produce some interesting insights.

Third, as a feature of second-generation $\mathrm{CB}$, Bulgaria has preserved the minimum required ratio in a rather standard way. ${ }^{16}$ Thus, whenever the BNB changes the required reserve ratio, it of course impacts on the credit sector. However, there exist (at least) two potential limits in studying changes in the required reserve ratio instrument. On the one hand, variability in this indicator becomes econometrically interesting only in the last few periods. For example, Nenovksy and Hristov (2002) note that the ratio is used "quite sparingly", since it was modified for the first time in July, 2000, from 11 per cent (its initial value, established in 1997) to 8 per cent. Nowadays, the last two decisions were taken on 1 September, 2007 (from 8 per cent to 12 per cent, to cool down the rapidly expending lending market) and very recently, on 1 December, 2008 (from 12 per cent to 10 per cent, to refinance the banking system). On the other hand, since most of banks playing on the Bulgarian market are foreign (branches or affiliates of major banks), these changes have little effect on their activity and moreover on the Bulgarian economy. Data show that following the September 2007 raise in the required reserve ratio, banks compensated this crowing-out effect with resources from abroad, so that credit supply did not significantly fall. On the contrary, the 2008 reduction did not provide the expected liquidity for the Bulgarian economy, since banks transferred outside Bulgaria the liquidity surplus. Despite this kind of difficulties, there exists an interesting attempt by Nenovsky et al. (2001) to compose an index reflecting changes in both the level and the basis on which this ratio is interfering.

Fourth, in Bulgaria, the Government has an account (that may include, for example, revenues from taxes and/or privatizations) with the National Bank, and resources in this account enter the official reserve accountancy. ${ }^{17}$ Thus, anytime the Government makes important deposits or withdrawals from this account, it implicitly changes the amount of official reserves, with potential effects on the economy (see the analysis in Nenovsky and Hristov, 2002). However, one may

\footnotetext{
${ }^{16}$ The same holds for Estonia, while in the former CB in Argentina, commercial banks were holding a share of their reserves in high-liquid US securities.

${ }^{17}$ The presence of this Government Account in the balance sheet of the BNB is another feature of secondgeneration $\mathrm{CBs}$, and exists also in the $\mathrm{CB}$ in Lithuania.
} 
contest that changes in Government Account with the National Bank should be considered as "monetary" shocks. In our view, they are hardly monetary shocks, since, even though these changes affect first monetary conditions, one may doubt that the Government proceeds to this kind of changes for monetary objectives (for example, to lower inflation expectations). On the other hand, it is difficult to treat them as "pure" fiscal shocks, since they influence monetary conditions first, before the real economy. Therefore, classifying changes in the Government Account as monetary or fiscal shocks is, in our view, still an open discussion.

Finally, the BNB has managed to conserve, to a certain extent, a Lender of Last Resort (LOLR) function (second-generation CBs feature). ${ }^{18}$ This service is strictly limited to resources up to the level of National Bank excess reserves, since the suspension of $\mathrm{CB}$ principles may attempt to the main goals of the $\mathrm{CB}$ (credibility and stability, see Ho, 2002); thus, at any time, currency is still 100 per cent backed up by reserves. Consequently, the LOLR in Bulgaria should be understood as a limited financing at a penalty rate, and not as a free financing at a penalty rate. The financing is done exclusively against "good" collaterals, only for banks that experience liquidity problems which are not caused by insolvency, and the repayment is not supposed to exceed 3 months. A detailed functioning of the LOLR mechanism is provided by Berlemann and Nenovsky (2004).

To summarize, while there exist some works on the LOLR function, more information is needed in order to deal with the required reserve ratio or the Government Account effects on the Bulgarian economy. Given that the EU is the main trade partner of the Bulgarian economy (more than 60 per cent), we also disregard exchange rate effects and we focus in what follows on the ECB interest rate changes as the main cause of shocks affecting Bulgaria.

\section{Data and Methodological Considerations}

To investigate monetary policy transmission in the Bulgarian economy, we consider a multivariate representation of the variables under investigation and carry out the recently developed technique based on generalized impulse response (GIRF) analysis, proposed by Pesaran and Shin (1998). Subsection one describes the data and examines the time series properties of variables to be included in the model, while subsection two discusses the modeling strategy.

${ }^{18}$ The LOLR function (as well as the required reserve ratio) is also conserved in the CB in Lithuania. 


\section{A. Data Set and Unit Root Tests}

Data are quarterly and cover the period Q3:1999 until Q4:2006, leading to 30 observations. Even if Bulgaria introduced the CB on 1 July, 1997, we use data starting from the $3^{\text {rd }}$ quarter of 1999 , to allow for variables to "stabilize" after this important shock. For example, changes in consumer prices (inflation) greatly oscillate among high values (65.7 per cent change in Q1:1998 relative to Q1:1997) and negative values (-0.9 per cent change in Q2:1999 relative to Q2:1998). ${ }^{19}$

As detailed above, since changes in Bulgarian monetary variables are not discretionary-decided, we turn our attention to the ECB refinancing interest rate. However, changes in the ECB interest rate are too rare to produce the necessary amount of variability in our analysis, and, in line with other studies (see, e.g. Peersman and Straub, 2004, or Reynard, 2007), we use the LIBOR EUR 3 month interest rate $\left(i^{\mathrm{EU}}\right)$.

We look at the impact of the $\left(i^{\mathrm{EU}}\right)$ on four variables, which we select by following two goals. On the one hand, we aim studying the response of most important monetary variables (since little is known about their behavior in a CB monetary system) and real variables. On the other hand, we restrict our benchmark VAR to five variables, since results are already affected by using a rather reduced number of observations.

The four remaining variables in our benchmark VAR are the following. First, we consider the Bulgarian interest rate $\left(i^{B G}\right)$, defined as the "money market rate" (three months maturity). Indeed, given the CB in Bulgaria, the BNB has no interference on this interest rate and $i^{B G}$ is considered to properly characterize the credit market stance. Second, we focus on a broad money indicator $M 3$, defined as the annual quarter-to-quarter growth rate of nominal $M 3$. To capture the effects on prices, we use the annual (quarter-to-quarter) growth rate of consumer prices (inflation) $I P C .^{20}$ Finally, to look for some real economy effects, we include the annual (quarter-toquarter) growth rate of real output (GDP), denoted by $Y$. All these variables, as well

\footnotetext{
${ }^{19}$ Even if data are available until Q2:2008, we restrict our sample before 2007. Indeed, starting 1 January, 2007, Bulgaria entered the European Union and a structural break should probably be accounted for in our econometric model. However, since we would be left with only six observations above this potential break, our results would be of course not very reliable. In a recent analysis of the credit sector in Bulgaria, Nenovsky et al. (2008) select the same time period (1999-2006) and for similar reasons. ${ }^{20}$ Lavrac (2004) discusses the role of inflation targeting in the Czech Republic, Hungary and Poland, and concludes that the appropriate measure for inflation is the "headline inflation rate" (the change in consumer price index and not inflation net of regulated prices). See also Orlowski (2000) and Corricelli et al. (2006).
} 
as the LIBOR EUR 3 month interest rate, come from the BNB dataset.

The first step of the analysis is to look at the macroeconomic data univariate properties. As it is now widely recognized, unit root testing is a mandatory exercise to be carried out prior to econometric modeling, since macroeconomic series are often trended or affected by persistent innovations to the process. Two classes of tests deal with this problem: unit root tests (see Ng and Perron, 2001) and stationarity tests ${ }^{21}$ (the most popular are the Kwiatkovski-Phillips-Schmidt-Shin KPSS, 1992, and the Leyborne-McCabe LMC, 1999). As recently stressed by Carrion-i-Silvestre and Sanso (2006), the main drawback of stationarity tests is the difficulty entailed by the estimation of the long-run variance needed to compute them. We follow their recommendations and apply the KPSS test using the procedure developed by Sul-Phillips-Choi (SPC, 2005) to estimate the long-run variance. This strategy involves less size distortion compared to the LMC test, while preserving reasonable power.

The results of the KPSS tests, reported in Table 1, indicate that the null stationarity hypothesis around a constant or around a linear trend root cannot be rejected at the five percent level of significance, for all macroeconomic series under consideration (the first five appear in the benchmark model, the remaining are used in the robustness analysis). Therefore it seems reasonable to treat all series under consideration as $I(0)$ processes.

\section{B. Methodological Considerations}

Since all series taken in level are integrated of order zero, it is possible to investigate the dynamic relationships among our set of variables in a VAR model using innovation accounting methods such as impulse response functions. ${ }^{22}$ However, the standard method developed by Sims (1980) has been criticized because results based of IRFs crucially depend on the "orthogonality assumption" and might differ markedly on the ordering of the variables in the VAR. Since evidence on the order of the considered variables is still crude under a CB monetary system, we may enhance the robustness of our results by implementing the recently developed "generalized" impulse response functions (GIRFs)

\footnotetext{
${ }^{21}$ In contrast to unit root tests, stationarity tests specify the null hypothesis of stationarity against the alternative of non-stationarity, so they can be seen as the reversal complement of the unit root tests.

${ }^{22}$ We illustrate in Appendix 1 the inverse roots of the characteristic AR polynomial. All (inverse) roots have modulus less than one (lie inside the unit circle), confirming that the estimated VAR is stable or stationary.
} 
Table 1. Stationarity Tests for Macroeconomic Series ${ }^{(a)}$

\begin{tabular}{ccc}
\hline Series & KPSS with Constant $^{(\mathrm{b})}$ & KPSS with Time Trend $^{(\mathrm{b})}$ \\
\hline ECB Interest Rate (IEU) & 0.345038 & 0.125566 \\
Money Market Rate (IBG) & 0.350640 & 0.132242 \\
Money BG (M3) & 0.073283 & 0.067855 \\
Inflation BG (IPC) & 0.172807 & 0.123543 \\
Output BG (Y) & 0.322619 & 0.082016 \\
\hline Exports & 0.109761 & 0.064466 \\
Imports & 0.097958 & 0.090447 \\
Private Consumption & 0.375273 & 0.146567 \\
Private Investment (GFCF) & 0.160808 & 0.147642 \\
Government Expenditure & 0.390122 & 0.078622 \\
$\Delta$ (Public Debt/GDP) & 0.234804 & 0.109402 \\
Deficit/GDP & 0.331638 & 0.138118 \\
World Prices & 0.138088 & 0.119962 \\
\hline cv (1\%) & Critical Values & Critical Values \\
cv (5\%) & 0.741 & 0.217 \\
cv (10\%) & 0.463 & 0.148 \\
\hline
\end{tabular}

(a)We apply the KPSS test using the procedure of Sul et al. (2005) to estimate the long-run variance. (b)We have used the AIC criterion to select the order of the autoregressive correction with pmax $=\operatorname{int}\left[12(T / 100)^{1 / 4}\right]$. We report the finite sample critical values drawn from the response surfaces in Sephton (1995). The null hypothesis of the KPSS test is "stationarity around a constant or around a (linear) time trend".

suggested by Pesaran and Shin (1998), which are insensitive to the ordering of the variables in the VAR (see Appendix 2). ${ }^{23}$

GIRFs have two appealing features. First, they are invariant to any re-ordering of variables in the VAR and they provide therefore more robust results than the orthogonalized technique. Second, since no orthogonality assumption is imposed, GIRFs allow exploring the initial impact response of each variable to shocks to any of the other variables. The ability of the GIRFs to capture these immediate responses of endogenous variables to shocks is clearly useful, especially when information is quickly assimilated, which is usually the case in a CB.

\footnotetext{
${ }^{23}$ For robustness issues, we compare GIRFs with IRFs from a SVAR (see section IV.B).
} 


\section{VAR Investigation and Examination of Dynamic Responses}

In the first sub-section we illustrate results in the benchmark VAR, while the second sub-section explores the robustness of our findings.

\section{A. The Benchmark Model}

Since our results are based on GIRFs, the order of variables in the VAR is unimportant. Let us suppose, without loss of generality, the following transmission scheme.

The continuous arrows denote the transmission mechanism in our benchmark case. An ECB interest rate $\left(i^{E U}\right)$ shock is considered to impact first the Bulgarian interest rate $\left(i^{E U}\right)$. Changes in interest rate $i^{B G}$ are supposed to affect the growth rate of real activity (output), followed by changes in consumer pricess IPC and in domestic nominal money growth $M B .^{24}$

Before implementing a generalized impulse response analysis, we must choose the optimal lag length in the benchmark VAR. Our selection is based on the LR test and four information criteria (see Appendix 3). According to information criteria and the LR test, we chose a lag 2. Appendix 1 reports the inverse roots of the AR characteristic polynomial of the estimated VAR and clearly confirms its stationarity, since all roots lie inside the unit circle (see Lütkepohl, 1991). Consequently, the estimated VAR may be used for a generalized impulse response analysis. ${ }^{25}$ To check the quality of the multivariate estimation, we performed several test concerning the serial correlation (LM tests), as well as ARCH tests and the Jarque-Bera normality test. Results in Appendix 3 indicate that the VAR model is well behaved and not subject to misspecification, since all usual hypotheses concerning the residuals of each equation are verified. ${ }^{26}$

Figure 1. Transmission Mechanism of a Shock on the ECB Interest Rate

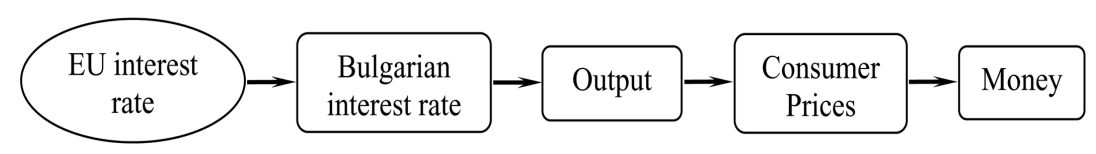

\footnotetext{
${ }^{24}$ According to KPSS stationarity tests in Table 1, all series are considered in level and we include a constant.

${ }^{25}$ Since (i) all series of our database are integrated of order zero and (ii) the inverse roots of the characteristic AR polynomial of the estimated VAR all lie inside the unit circle, the question of cointegration testing between those series is of course not relevant here.

${ }^{26}$ Finally, we report that the re-estimation of the VAR by recursive least squares and the implementation of Chow tests confirm the stability of the parameters for the estimation period (results are available upon request).
} 
Figure 2 below depicts the results of a generalized impulse response analysis for the benchmark VAR, together with their bootstrapped 95 per cent confidence bands.

We observe first that an exogenous increase in the ECB interest rate initially increases the Bulgarian interest rate. However, the Bulgarian interest rate adjustment is very irregular. Money positively responds in the short-run, which is

Figure 2. Generalized Impulse Response Functions in the Benchmark Model

Response to Generalized One S.D. Innovations \pm 2 S.E.
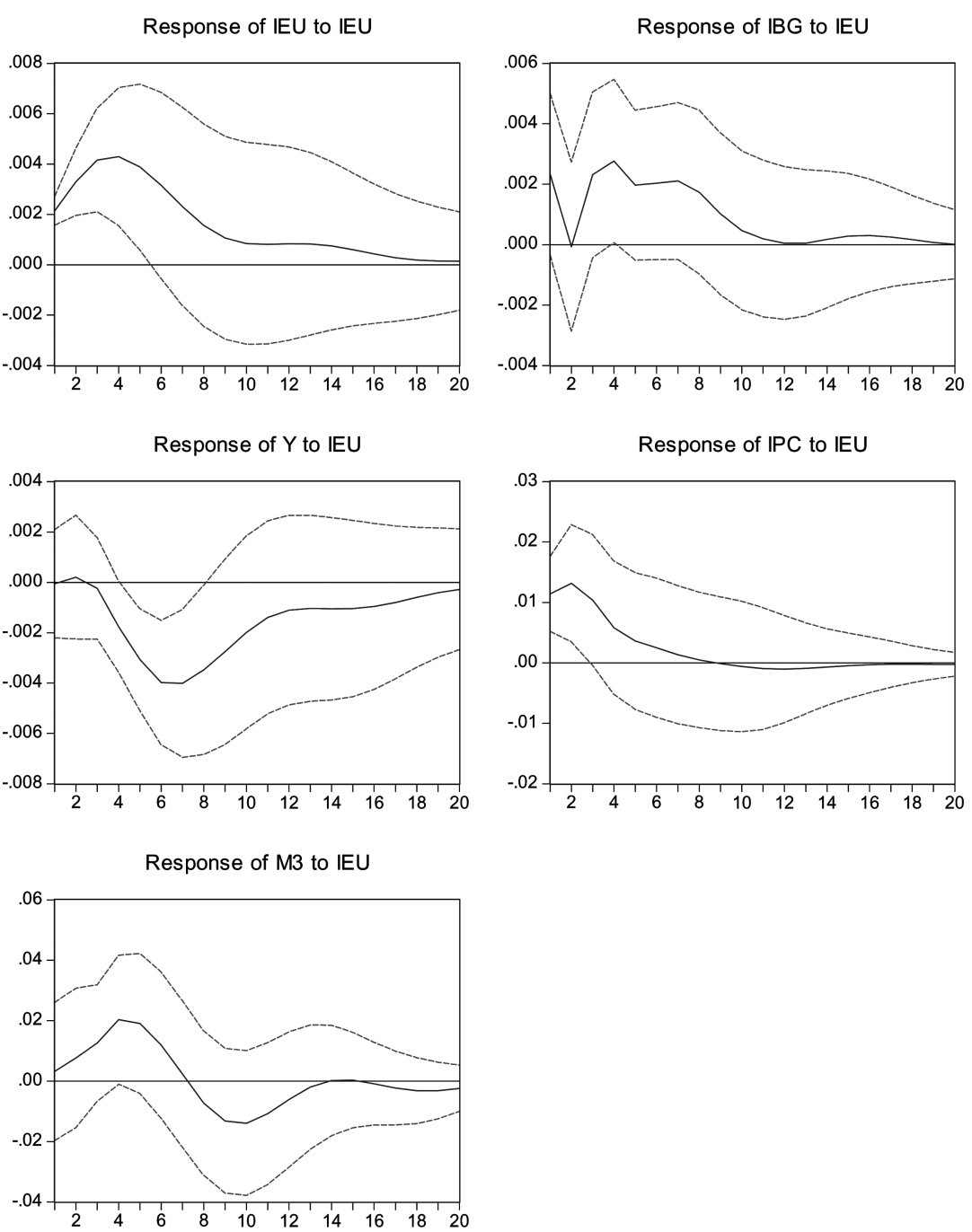

Note for all VARs: The fact that GIRFs to shocks stabilize and come back towards zero indicates on the one hand, that the VAR model is correctly specified and, on the other, that all macroeconomic series are integrated of order zero. 
in accordance to the CB functioning. Indeed, since the money stock in Bulgaria is money-demand determined, the raise in nominal $M 3$ describes a rise in domestic inflation, which is one of the key factors determining money demand. Notice that this effect is supported by evidence in EFN (2004). However, what is more important, is that money adjustment is irregular (cyclical), closely related to the adjustment of the domestic interest rate.

Our interpretation of these two results builds on the idea that both Bulgarian interest rate and money are endogenous with respect to external monetary shocks. Irregularities in their adjustment may reproduce the fact that, following an external shock, both aggregates take some time to stabilize, because, compared to countries with a high degree of autonomous monetary policy, the BNB has no (or very reduced) discretionary impact on either the domestic interest rate or money. Lacking the information that this kind of institutional anchor is usually supplying, firms and households need more time to form expectations, and even their expectations might differ from those that would have been made in the presence of a "traditional" Central Bank. Our results are particularly close to empirical evidence in EFN (2004) for Estonia, a country with a CB monetary system.

Moreover, we depict in Figure 3 the LIBOR EUR 3 months interest rate $\left(i^{E U}\right)$ and the Bulgarian money market rate $\left(i^{B G}\right)$, both in quarterly data for the 1999:Q3 2006:Q4 period.

Data in Figure 3 seem to confirm results in our benchmark VAR, since, for a certain period of time, the LIBOR rate and the Bulgarian interest rate were disconnected. This reflects the fact that, in a $\mathrm{CB}$, changes in the interest rate or

Figure 3. The ECB LIBOR EUR 3 Months (IEU) and the Bulgarian Interest Rate (IBG)

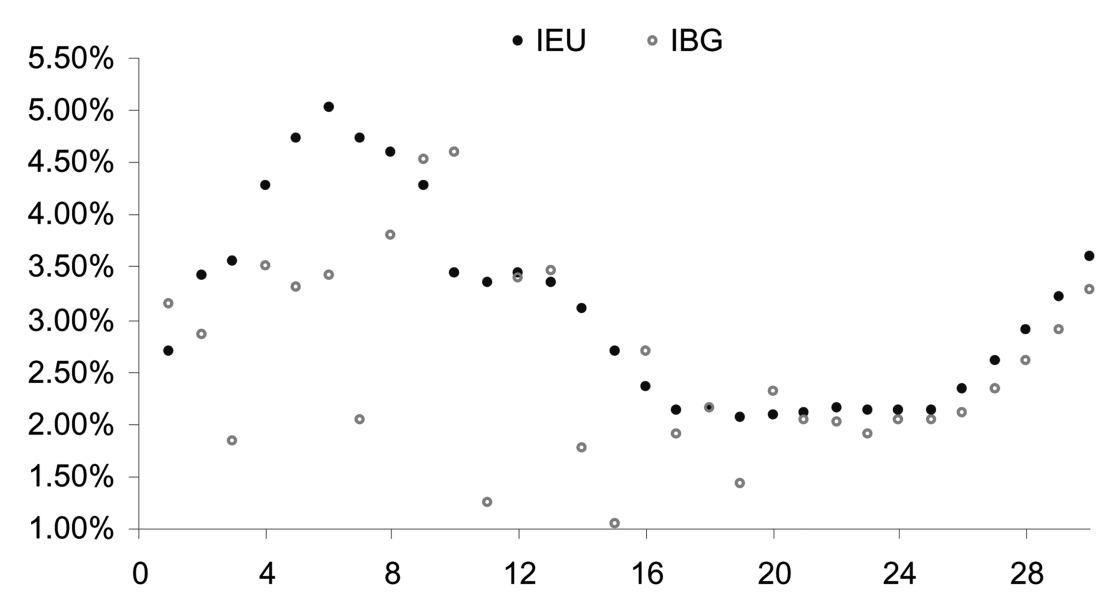


monetary aggregates are not exogenous, but they mainly reflect the endogenous development of the two variables, subject to several factors, among which: (i) economic development, (ii) external financing constraints, (iii) different arbitrage conditions and, of course, (iv) the stance of the domestic financial market. Concerning this last point, the banking system experienced several "arrangements" in the first years, including the existence of high (above requested) liquidity ratios and the progressive reduction of high risks exposures and of the share of credits to the public sector. ${ }^{27}$ This transition period may well explain the short-run disconnection with respect to the EURIBOR, especially since Bulgarian financial market became more integrated with the EU financial market only in the last years, ${ }^{28}$ boosted by the adoption of several measures. ${ }^{29}$ These facts confirm that modern CBs (as the one in Bulgaria) should be seen as a long-run relationship between monetary conditions and not as a rapid current account adjustment mechanism (Lättemäe, 2003).

Finally, another point that could sustain our results is that the domestic interest rate adjustment is more rapid, compared to evidence in EFN (2004) for former acceding countries with some autonomous degree for monetary policy (the Czech Republic, the Slovak Republic or Slovenia). Thus, according to the response of Bulgarian variables, foreign shocks are rather short-lived, which is another feature usually defended in a CB monetary system as the one in Bulgaria. For example, concerning monetary transmission in Estonia, Lättemäe (2003) finds that the effects of external shocks in financial conditions (like the ECB interest rate), are shortlasting (see also Bems, 2001), result confirmed by Vetlov (2003) for Lithuania.

Building on this interpretation for the behavior of monetary aggregates, we can withdraw very interesting information about output behavior. Notice that output does not significantly respond for around three quarters, which is again an interesting result. Since we impose no stickiness constraint for output reaction with

\footnotetext{
${ }^{27}$ In a second-generation $\mathrm{CB}$, the bank supervision and regulation are essential, as confirmed by the existence of a Banking Department within the BNB, which performs exclusively this kind of tasks.

${ }^{28}$ The process of bank privatisation in Bulgaria was achieved in 2003 , as the number of foreign commercial banks increased from 14 (1997) to 35 (2003), and their share in total banking assets evolved from 32.7 per cent (1996) to 72.8 per cent (2005). Furthermore, the largest majority of foreign banks are EU-based.

${ }^{29}$ For example, on 2 June, 2003, the BNB introduced the RINGS system (Real-time INterbank Gross Settlement) system which allowed for real-time settlement between banks (previously, settlements were allowed at fixed ours, several times a day). This decision came together with the suppression of the 0.5 per cent fee on exchange operations and with the allowance to exchange LEV against EURO brought from abroad (and vice versa).
} 
respect to monetary shocks (changes in $i^{E U}$ ), output lack of reaction cannot come from a stickiness hypothesis, but is rather a stickiness result. One possible explanation may be that, because of irregular adjustments for monetary variables, real economy reacts with some delay, since additional information about the evolution of endogenous adjustments of monetary variables is needed. After a period close to three quarters, our estimations exhibit the usual decrease in output growth. However, this negative effect is absorbed more quickly compared with economies with higher monetary autonomy, but in line with results for countries under CB: Lättemäe and Pikkani (2001) conclude that the effects of an ECB interest rate shock on the real economy in Estonia were rather small, in line with the conclusions of Babich (2001) for Latvia.

To sum up, our results suggest that, as monetary variables are not controlled by the BNB (they are endogenous or market-driven), firms and households may lack some information compared to the case when the behavior of these two variables would somehow be controlled by Monetary Authorities. In this case, both domestic interest rate and money present an irregular adjustment, a result supported by data in Figure 3, showing that domestic interest rate is disconnected from the evolution of the ECB interest rate in the short-run. ${ }^{30}$ However, notice that this adjustment takes less time compared to more autonomous economies, reproducing the fact that $\mathrm{CB}$ economies adjust quickly. In this case, output lacks reaction in the initial periods, and one may consider this as a "time-to-build-information" period for households and firms, with respect to the evolution of endogenous monetary variables. Our results are in line with Carlson and Valev (2001) and Berleman and Nenovsky (2004), who also find that agents adopted a "wait-and-see" strategy following the introduction of the CB. Finally, output decrease is important, but its adjustment is short-lived, confirming the idea that external monetary shocks have short-lasting impacts on real activity in a CB.

\section{B. Robustness Tests}

Before presenting robustness tests, we would like to discuss the issue of comparing GIRFs and SVARs. As we have already stated, the advantage of GIRFs

\footnotetext{
${ }^{30}$ Our results corroborate previous evidence confirming the absence of the Automatic Mechanism in Bulgaria, contrary to Estonia and Lithuania (see Miller, 1999, Nenovksy and Hristov, 2002). Hanke and Sekerke (2003) consider that the existence of some form of monetary discretion (through the required reserve ratio, the Government Account and the LOLR) may lead to credibility problems and to the lack of AM in Bulgaria.
} 
is that responses are immune to the ordering of the variables, which is rather important when there is little knowledge about this order (as in our CB setup). However, this also implies giving up the advantages of SVARs, namely the use of economic-derived constraints to achieve SVAR identification. ${ }^{31}$

Suppose now the transmission mechanisms illustrated in Figure 1, following a shock on the ECB interest rate. To capture the transmission mechanism $i^{E U} \rightarrow i^{B G} \rightarrow Y \rightarrow I P C \rightarrow M B$, we may use a recursive SVAR, with variables specified in this same order. Under this recursive identification, shocks in $i^{B G}$ (more precisely, responses of $i^{B G}$ to changes in $i^{E U}$ ) contemporaneously affect $i^{B G}, Y, I P C$ and $M 3$, changes in $Y$ contemporaneously affect $Y, I P C$ and $M 3$, changes in IPC contemporaneously affect $I P C$ and $M 3$, while changes in $M 3$ contemporaneously affect $M 3$ exclusively. ${ }^{32}$ Illustrations for IRFs (available in Appendix 4) clearly support previous evidence: Bulgarian monetary variable responses are still rather irregular and output is still sticky in the first periods. ${ }^{33}$

Finally, remark that one may contest the transmission mechanism illustrated in Figure 1, in particular after the Bulgarian output. Consequently, we have estimated a SVAR model in which IPC and $M B$ change order (MB is placed fourth and IPC is placed fifth). We report that allowing for this second order in a SVAR does not qualitatively change main results, namely domestic monetary variables and output responses (results are available on request).

Coming back to our benchmark VAR, we now consider some experiments to check its robustness by estimating different alternative VAR models. ${ }^{34}$

\footnotetext{
${ }^{31}$ For a discussion on SVARs identification, see Stock and Watson (2001). While the SVAR technique has recently been used for rather heterogeneous topics (Blanchard and Perotti, 2002, for fiscal policy, or L' Horty and Rault, 2004, for the labor market), its application concerns mainly monetary policy effects (on consumption, Crowder and Wohar, 2003, on investment, Mojon et al., 2002, or on core inflation, Quah and Vahey, 1995), and in particular monetary policy transmission (see Sims, 1992, and the survey of Christiano et al., 2000).

${ }^{32}$ Putting $i^{U E}$ first implies that changes in other variables do not contemporaneously affect the ECB rate.

${ }^{33}$ Technically speaking, Pesaran and Shin (1998) have shown that for a non-diagonal error variance matrix, the orthogonalized and the GIRFs coincide only in the case of the impulse responses of the shocks to the first equation in the VAR. Since the only shock we study (following our economic analysis above) is the one on the EU interest rate (the first variable in the VAR), the IRFs in the presented recursive SVAR are identical to the GIRFs. However, from an economic viewpoint, one should retain that our results are robust in two specifications: in a recursive SVAR with variables placed in an intuitive order and when computing general response functions that are unaltered by the ordering of the variables.

${ }^{34}$ We do not report again (as for the benchmark VAR) the inverse roots of the characteristic AR polynomials of the alternative estimated VAR, but we confirm that in each case the estimated VAR is stationary (results are available on request).
} 


\section{(1) The Inclusion of Control Variables}

In this sub-section, we aim at estimating VAR models that include several control variables, namely outside the VAR structure. First, we wish to investigate if introducing a world price variable may solve the price puzzle (Sims, 1992). Different estimations with either the variable external prices (defined as an average of oil, metal, non-food and food prices) or the variable world commodity prices, failed to remove the initial raise in prices following a positive shock on the ECB rate. ${ }^{35}$ Instead, as Figure 4 suggests, introducing these control variables does not qualitatively change GIRFs, compared to results in our benchmark model.

An interesting fact is that the positive reaction of inflation is more important in the short-run compared to the increase in nominal money. Consequently, in the short-run the real money stock decreases, following the increase in the Bulgarian interest rate. We can compute real money $M B R$ reaction in two ways (results are of course not identical, but very close): first, as the difference between the two response functions of nominal $M 3$ and inflation (IPC), ${ }^{36}$ second as a response function (following a shock on the EU interest rate) in a similar five-variables VAR, except that we replace nominal $M 3$ with real $M 3$ (results are very closely related and available upon request).$^{37}$ The fact that real money decreases in the short-run may be in accordance with the existence of a CB monetary system: when domestic interest rate rises, real money demand decreases (according to the liquidity function). Given the fact that in a CB the money supply is money-demand driven, this may explain the negative response of real money supply following a raise in the Bulgarian interest rate.

Second, we explore the sensitivity of our benchmark results with respect to the presence of several control fiscal variables. On the one hand, we consider the ratio of public deficit-to-GDP (see Figure 5). On the other, we introduce the variation of the public debt-to-GDP ratio (see Appendix 5). ${ }^{38}$ As confirmed by Figure 5 and Appendix 5, our results are qualitatively unchanged when accounting for these two

\footnotetext{
${ }^{35}$ However, previous studies on different CBs have also been unsuccessful in solving the price puzzle when considering external prices or world commodity prices (see, for example, EFN, 2004, for Lithuania).

${ }^{36}$ Indeed, the growth rate of real money $\Delta(M 3 R) /(M B R)$ equals the difference between the growth rate of nominal money $\Delta(M 3) /(M 3)$ and inflation $\Delta(I P C) /(I P C)$.

${ }^{37} \mathrm{We}$ find the same result in a four-variable VAR in which real money $M B R$ replaces nominal money $M 3$ and inflation IPC (see evidence below in sub-section 3.).

${ }^{38}$ During this period, we observe a significant reduction (a pronounced negative slope) of the Bulgarian public debt-to-GDP ratio. To correct eventual non-stationarity problems, we use the first order difference of the ratio, which turns out to be stationary (see Table 1).
} 
Figure 4. GIRFs in the Benchmark Model when Controlling for the World Commodity Prices

Response to Generalized One S.D. Innovations \pm 2 S.E.

Response of IEU to IEU

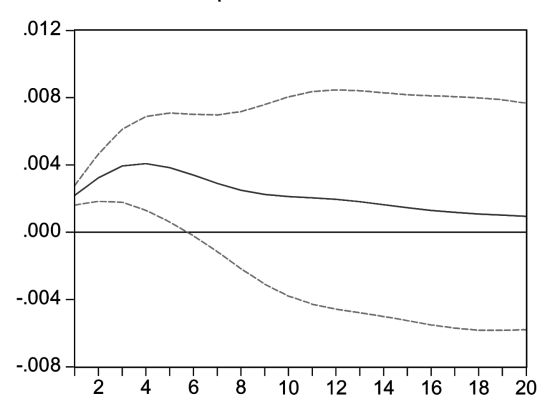

Response of $\mathrm{Y}$ to IEU

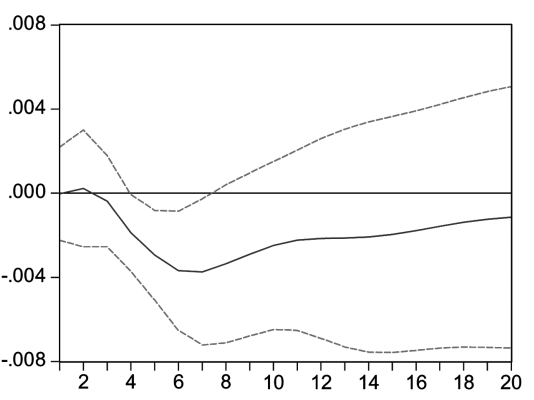

Response of M3 to IEU

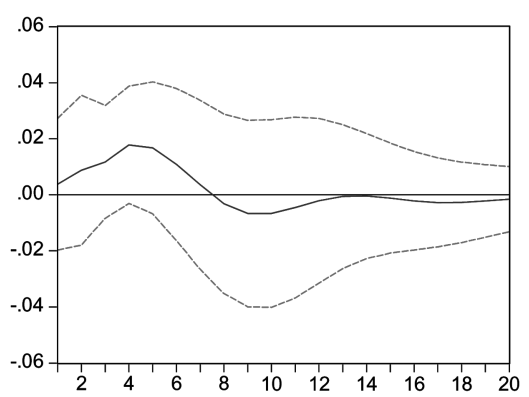

Response of IBG to IEU

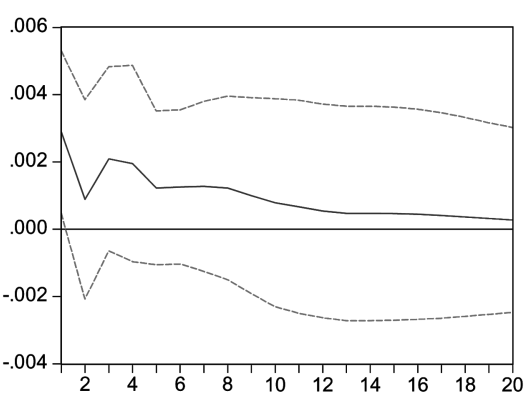

Response of IPC to IEU

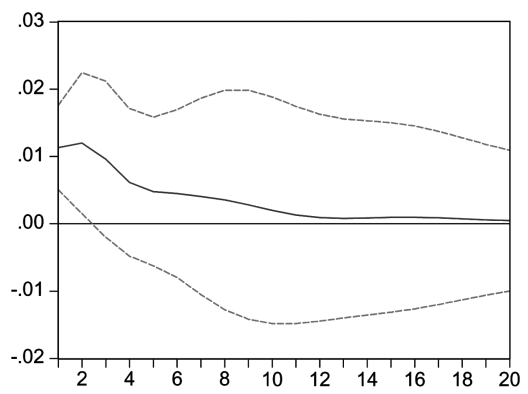

fiscal variables. ${ }^{39}$ Output still does not respond in the short-run, while Bulgarian interest rate and money supply responses are even more irregular (cyclical), supporting our previous results.

(2) The Replacement of Output by Other Variables from Real Economy We propose in this sub-section several VAR models in which we replace output

${ }^{39}$ Our results are close to EFN (2004), in the way that controlling for these fiscal variables is powerless in solving the price puzzle in the three Baltic States. 
Figure 5. GIRFs in the Benchmark Model when Controlling for Public Deficit-to-GDP Ratio Response to Generalized One S.D. Innovations \pm 2 S.E.
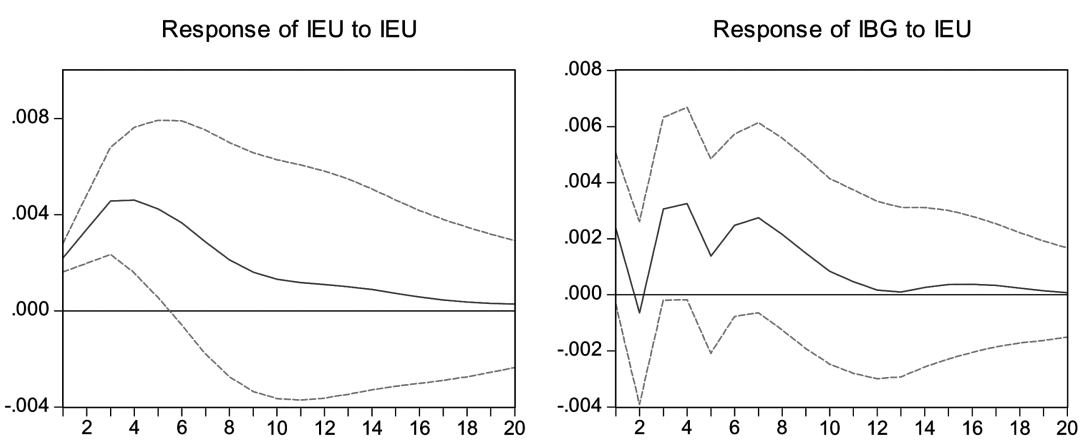

Response of $Y$ to IEU

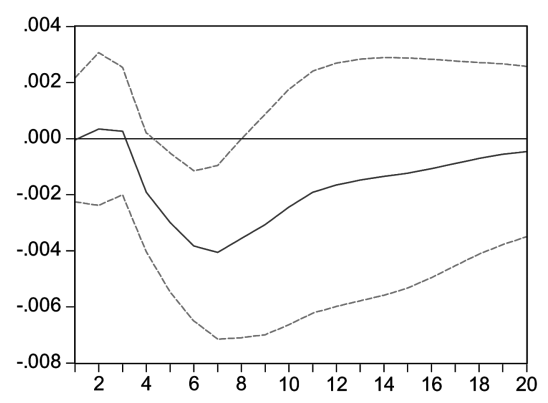

Response of IPC to IEU
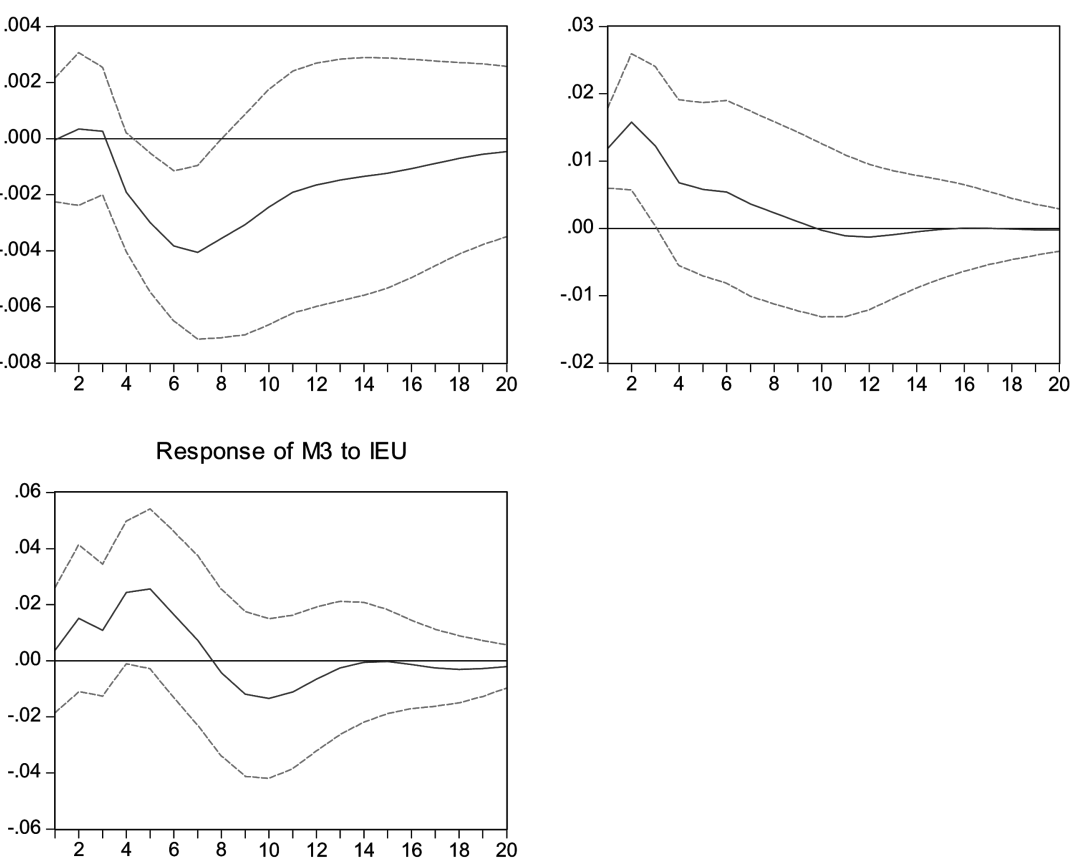

by other variables from the real economy. Our goal is to search if, considering different variables from the real economy, changes significantly our results. Thus, we focus on private consumption, gross fix capital formation, public expenditure, imports and exports, all in quarter-to-quarter yearly growth rate, all extracted from the BNB database.

We report that our benchmark results remain unchanged and, consequently, we depict in Figure 6 exclusively the new variable introduced in the VAR (the variable which replaces output). Following a positive shock on the ECB interest rate, 
private consumption decreases less than output, confirming that consumption is smoother than output. ${ }^{40}$ Concerning public expenditure, we observe that following a raise in the ECB interest rate, government reacts counter-cyclically by positively adjusting public spending starting from the impact, in order to partially counterbalance the negative effect in output. Although the public spending raise is vigorous on impact, its persistence is rather reduced in time. Finally, imports raise, and exports positively react on the impact, which is somehow counter-intuitive, since a higher domestic interest rate means a lower competitiveness. However, since (in our experiment) the magnitude of the response of the EU interest rate is higher, compared to the Bulgarian interest rate raise, the Bulgarian economy is relatively more competitive with respect to EU (and both economies are less competitive with respect to the rest of the world). Since the EU is the most important trade partner, this competitiveness gain may boost (however, for a very

Figure 6. GIRFs of Several Real Variables that Replace Output in the Benchmark Model
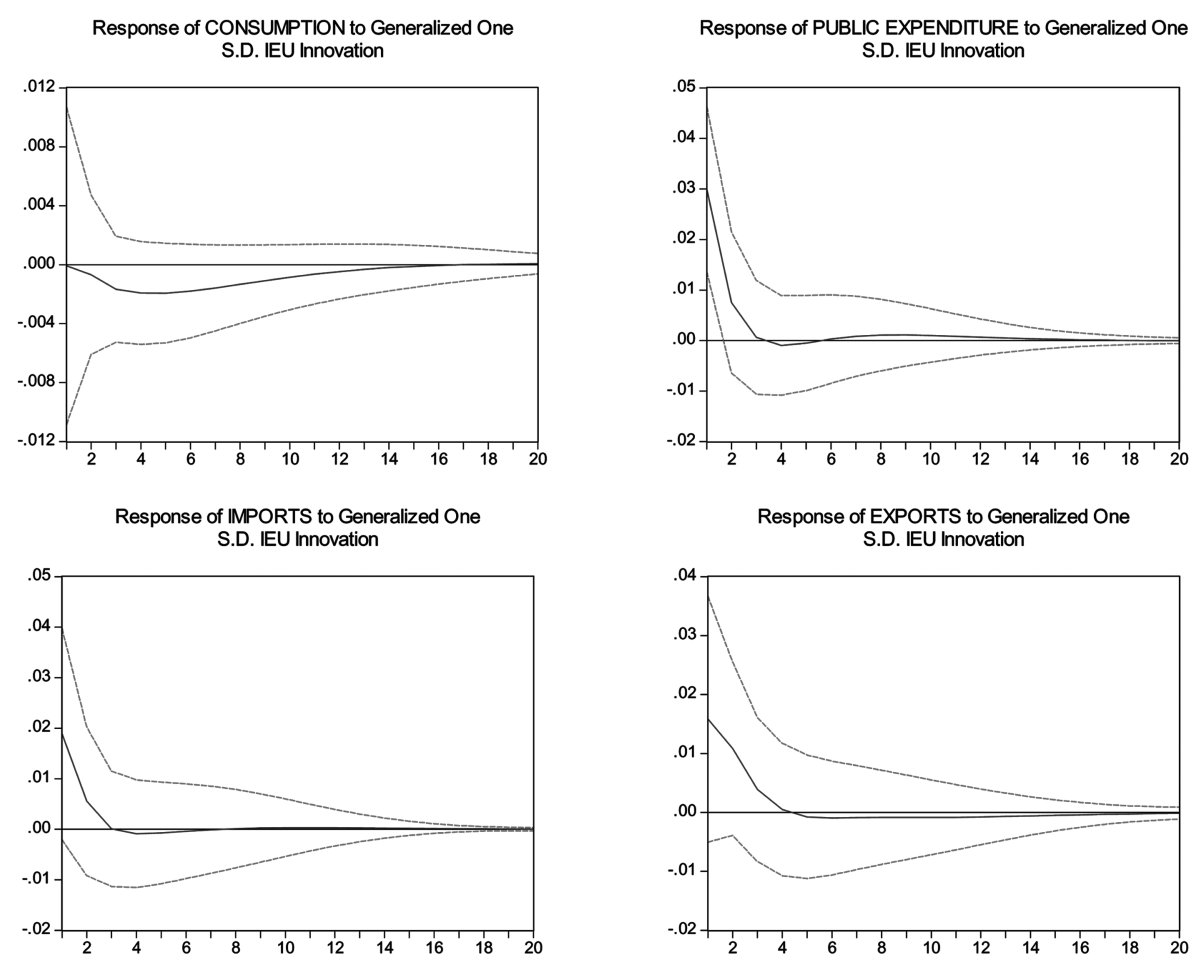

\footnotetext{
${ }^{40}$ To find if investment is more volatile than output, we performed several estimations using the gross fix capital formation (GFCF). Unfortunately, GFCF is extremely volatile in the first quarters of the sample and our attempts to shorten the sample by disregarding these initial values did not produce conclusive results.
} 
Figure 7. GIRFs in a Four-variables VAR (real money replaces nominal money and inflation)

Response to Generalized One S.D. Innovations \pm 2 S.E.
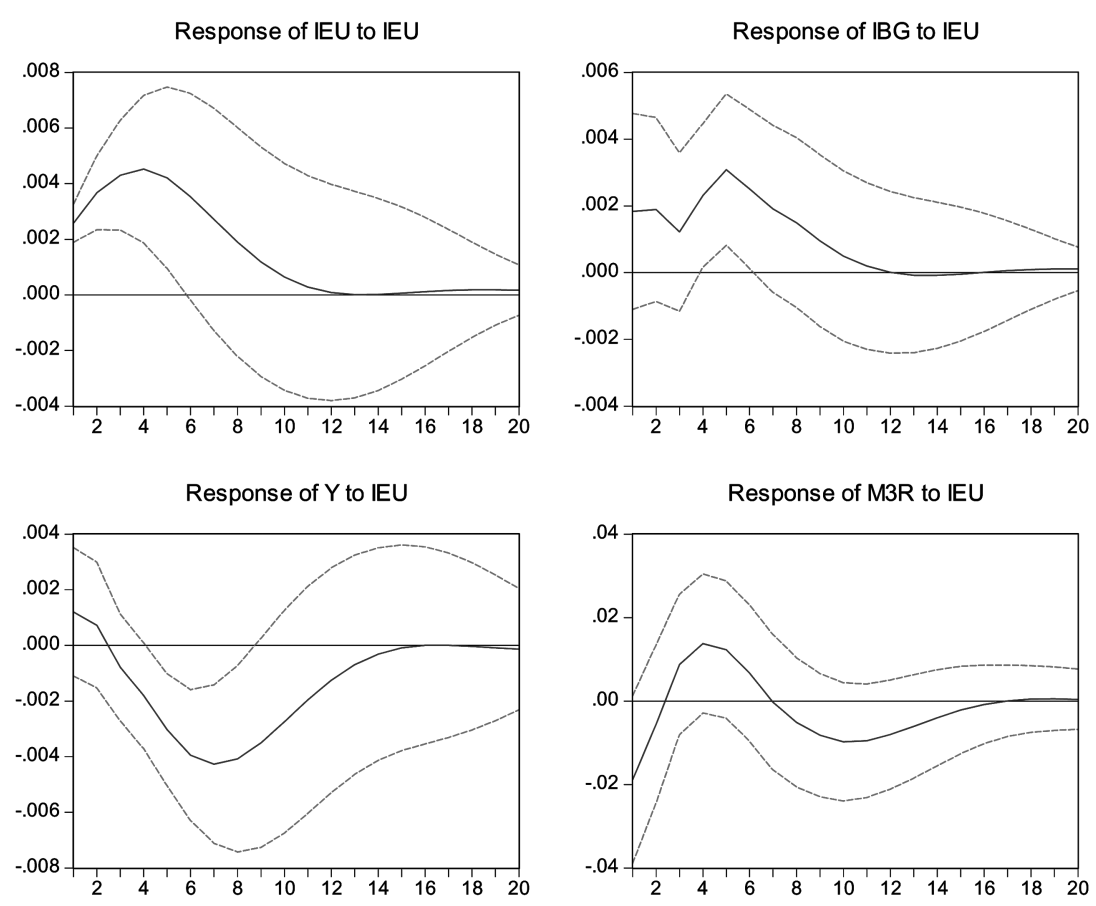

short period of time, since $i^{B G}$ quickly converges to $i^{E U}$ ) Bulgarian exports. Finally, one should keep in mind that exports and imports are highly related in Bulgaria, since a major share of exported goods (around 70 per cent) are produced with imported goods.

\section{(3) The Reduction of the Size of the Benchmark VAR}

One possible critique of our results may come from the fact that we are using too few observations. To deal with this problem, we may either increase the period of time (see the explanations above) or reduce the number of variables in the VAR. Concerning this second solution, the most intuitive transformation is to replace nominal money $M B$ and $I P C$ with real money $M B R$, in a four-variables $\operatorname{VAR}\left(i^{E U}\right.$, $\left.i^{B G}, Y, M B R\right)$.

According to Figure 7, following a positive shock on the EU interest rate, Bulgarian interest rate still presents an irregular short-run adjustment and the reaction of output is still fairly low in the first quarters. More important, real money $M B R$ negatively reacts to a higher interest rate and its adjustment is still 
cyclical, confirming our previous results (see Figures 2 and 4 and explanations after Figure 4).

Moreover, Appendix 6 illustrates reaction functions following a shock on $i^{E U}$ for two VARs. In the first model, we investigate the $i^{B G}$ response when abstracting from money-supply effects, in the four-variables VAR: $i^{E U}, i^{B G}, Y$ and IPC. Observe that our results are qualitatively unchanged: the domestic interest rate is disconnected from the $i^{E U}$ in the short-run, the response of output is weak in the first periods and inflation still moves upwards.

Since we found that the Bulgarian interest rate reaction is robust even if we do not take into account money supply, it would be interesting to check how money $M 3$ responds when $i^{B G}$ is absent from the VAR. This strategy could also be supported by the fact that most borrowing is taking place in the anchor currency. As with the previous two VARs, GIRFs in Appendix 6 clearly support conclusions from our benchmark VAR: output reactions is fragile in the first periods, inflation still raises, and, the most important, nominal money demand positively reacts in the short-run and follows a cyclical movement afterwards.

\section{Conclusion}

The goal of our study was to offer some new insights into monetary policy transmission in Bulgaria. The presence of a particular monetary system, namely a Currency Board, is a determining factor in analyzing monetary policy in Bulgaria. Consequently, we explored first the CB functioning in Bulgaria and the implications generated by adopting such a monetary system. In particular, since usual monetary instruments (the Bulgarian interest rate and money aggregates) are not settled discretionary (by Monetary Authorities), we questioned the possibility of defining a monetary shock and selected the ECB interest rate as the main source of monetary disturbances.

The econometric analysis performed on our data suggests the adoption of a VAR model, to study the effects of a change in the ECB interest rate on the domestic economy. The estimations of our benchmark model (based on GIRFs, thus invariant to the ordering of variables) emphasize that both Bulgarian interest rate and money follow the ECB rate dynamics in the medium-long-run only. In the short-run however, both aggregates exhibit a rather irregular response, and a possible explanation may involve their endogeneity. Effectively, under the $\mathrm{CB}$ in Bulgaria, these two aggregates are not "driven" by some discretionary behavior of 
the National Bank, but mainly by the domestic economic environment (the level of financial development, arbitrage conditions). Our findings for Bulgaria are in line with results in countries with no (little) monetary policy autonomy (Estonia, Lithuania and, to some extent, Latvia). Moreover, output does not react in the shortrun, following a change in the ECB interest rate. Since we did not impose a stickiness constraint on output behavior, this result may equally be explained by a "time-to-build" interpretation, namely that agents (influencing real economy) need time to collect enough information about future adjustments of monetary aggregates.

The conclusions of our benchmark model are robust to different specifications, including controlling for several variables (world commodity prices, public deficit or public debt), replacing output with other real-economy variables (private consumption, public expenditure, exports or imports) or imposing an ordering in a SVAR model. Our results still hold when restraining the number of variables with respect to the benchmark VAR, in order to compensate the relatively low number of available observations.

Concerning this last point, future research is of course needed in order to better assess the robustness of our conclusions. An interesting development would be to integrate in the sample the recent data (however, extreme caution is needed when considering data after the 2008 financial crisis). Benefiting of a larger sample may allow introducing more variables in the model (in particular, Euro Area inflation or real output), in order to derive some insights about the progress of the Bulgarian economy with respect to the integration in the European Monetary Union, which is expected to occur in the near future.

\section{Acknowledgements}

We would like to thank the Editor (Hwan Ho Lee) and two anonymous referees for very helpful comments on a previous version. Parts of the paper were written while Alexandru Minea was a research guest at the Bulgarian National Bank (BNB). He would like to thank Petar Chobanov, Jean-Louis Combes, Fabrizio Coricelli, Kalina Dimitrova, Nikolay Nenovsky, Lucian Orlowski and Patrick Villieu for their vital feedback on the CB topic. Financial assistance from BNB has been a stability factor in carrying out this research project. The opinions expressed in this study are those of the authors and do not necessarily reflect the position of the BNB. Of course, all remaining errors are ours. This paper was presented at the 
AFSE 2008 Congress in Paris and is a revised version of the William Davidson wp. No. 903.

Received 17 November 2008, Revised 6 February 2009, Accepted 11 February 2009,

\section{Appendix}

A.1: Inverse Roots of AR Characteristic Polynomial

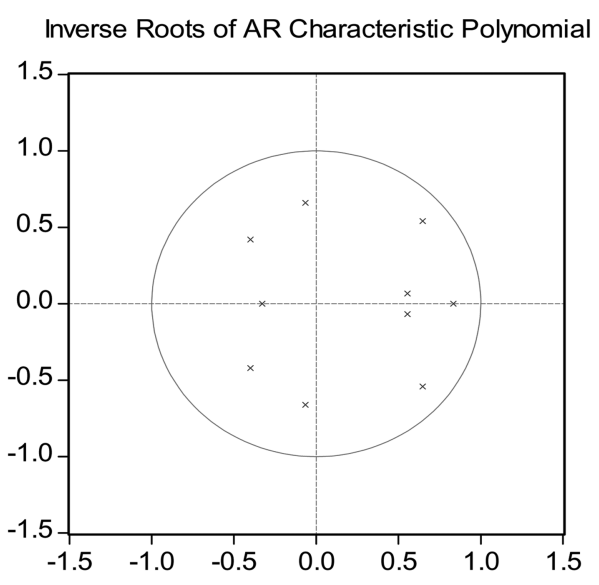

\begin{tabular}{cc}
\hline Root & Modulus \\
\hline $0.646566-0.540689 \mathrm{i}$ & 0.842848 \\
$0.646566+0.540689 \mathrm{i}$ & 0.842848 \\
0.832620 & 0.832620 \\
$-0.065460-0.660781 \mathrm{i}$ & 0.664016 \\
$-0.065460+0.660781 \mathrm{i}$ & 0.664016 \\
$-0.400235-0.420195 \mathrm{i}$ & 0.580303 \\
$-0.400235+0.420195 \mathrm{i}$ & 0.580303 \\
$0.553938-0.067591 \mathrm{i}$ & 0.558046 \\
$0.553938+0.067591 \mathrm{i}$ & 0.558046 \\
-0.329753 & 0.329753
\end{tabular}

Note: no root lies outside the unit circle, thus the VAR satisfies the stationarity condition

A.2: Technical Details for the Computation of GIRFs

Suppose that the internal dynamic of the $X_{t}=\left(X_{1}, \ldots, X_{n t}\right)$ 'vector can be suitably captured by the $\operatorname{VAR}(p)$ representation defined as the regression of the $X_{t}$ vector on its past:

$$
B(L) X_{t}=\varepsilon_{t}, t=1, \ldots, T, \text { with }\left\{\begin{array}{l}
E\left(\varepsilon_{t} \varepsilon_{t+s}\right)=\Omega, \text { for } s=0 \\
E\left(\varepsilon_{t^{\varepsilon}} \varepsilon_{t+s}\right)=0, \text { for } \quad s \neq 0
\end{array}\right.
$$

$B(L)=\left(I_{n}-\sum_{i}^{n} B_{i} L^{i}\right)$ is a polynomial matrix in $L$ (the lag operator), with $B(0)=I_{n}\left(I_{n}\right.$ the $n$-square unity matrix) and $\varepsilon_{t}=\left(\varepsilon_{1}, \ldots, \varepsilon_{n t}\right)$ ' is a $n$-dimensional vector of white noises (of variance-covariance matrix $\Omega$ ), such as shocks are contemporaneously correlated. The inverse of the roots $(z)$ of the characteristic equation $(\operatorname{Det}[B(z)]=0)$ are supposed to be of modulus strictly inferior to one (stationarity condition), allowing interpreting $\varepsilon_{t}$ as canonical innovations (namely as the part of $X_{t}$ which cannot be linearly explained by its own past).

Using the Wold representation it is possible to rewrite (A1) equivalently under 
the well-known moving average form:

$$
X_{t}=C(L) \varepsilon_{t}, t=1, \ldots, \mathrm{T}
$$

$C(L)=\left(I_{n}-\sum_{i=1}^{m} B_{i} L^{i}\right)$ is a polynomial matrix in $L$, which provides the dynamic effects of each innovation on each variable, with $C(0)=I_{n}$. The GIRF of $X_{i t}$ (e.g. the

A.3: Lag Selection and Other Tests for the Benchmark VAR Model

LR test (LR, column 1), final prediction error (FPE, column 2), Akaike information criterion (AIC, column 3), Schwarz information criterion (SC, column 4), Hannan-Quinn information criterion (HQ, column 5).

\begin{tabular}{cccccc}
\hline Lag & LR & FPE & AIC & SC & HQ \\
\hline 0 & NA & $6.30 \mathrm{e}-19$ & -27.71989 & -27.47992 & -27.64853 \\
1 & 118.7921 & $1.46 \mathrm{e}-20$ & -31.52480 & $\mathbf{- 3 0 . 0 8 4 9 9}$ & -31.09667 \\
$\mathbf{2}$ & $\mathbf{3 8 . 6 8 0 6 4}$ & $\mathbf{1 . 0 2 e - 2 0}$ & -32.09049 & -29.45082 & $\mathbf{- 3 1 . 3 0 5 5 8}$ \\
3 & 22.42913 & $1.61 \mathrm{e}-20$ & $\mathbf{- 3 2 . 2 7 7 6 5}$ & -28.43814 & -31.13596 \\
\hline
\end{tabular}

\begin{tabular}{cccc}
\hline Equation & LM $(4)^{\mathrm{a}}$ & ARCH $(4)$ & JB (2) \\
\hline${ }^{E U}$ & $0.27938(0.8861)^{\mathrm{b}}$ & $0.43418(0.7811)$ & $0.02937(0.9854)$ \\
$i^{B G}$ & $2.67600(0.0793)$ & $0.27515(0.8868)$ & $0.66062(0.7187)$ \\
$Y$ & $0.54309(0.7071)$ & $0.21663(0.9226)$ & $0.18322(0.9125)$ \\
$I P C$ & $1.74860(0.1994)$ & $0.39515(0.8074)$ & $0.06977(0.9657)$ \\
$M 3$ & $1.40970(0.2852)$ & $1.09790(0.4140)$ & $2.20200(0.3325)$ \\
\hline
\end{tabular}

Notes: a - LM (4) denotes Lagrange Multiplicator test of order 4; ARCH (4) denotes Autoregressive Conditional Heteroscedasticity test of order 4; and JB (2) denotes Jarque-Bera (with two degrees of freedom) normality test.

$\mathrm{b}$ - the number in brackets indicates the marginal asymptotic level, namely the probability to exceed the value of the computed statistic. Hence, for instance, a marginal asymptotic level of 88.61 per cent (0.8861) means that for a significance level smaller than 88.61 per cent, the null hypothesis of absence of residual serial correlation of order 4 cannot be rejected by data.

Bulgarian interest rate $i^{B G}$ ) to a unit (one standard deviation) shock in $X_{j t}(e . g$. the EU interest rate $\left.i^{E U}\right)$ is then given by $\operatorname{GIRF}_{i j, N}=\left(\sigma_{i i}\right)^{-1 / 2}\left(e_{\mathrm{j}} \Omega e_{i}\right)$ where $\sigma_{i i}$ is the $i$-th diagonal element of $\Omega, e_{i}$ and $e_{j}$ are selection vectors (with respectively the $i$-th and the $j$-th element equal to one and all other elements equal to zero) and $N$ is the horizon. 
A.4: IRFs in the Recursive SVAR Based on Cholesky Decomposition

Response to Cholesky One S.D. Innovations \pm 2 S.E.
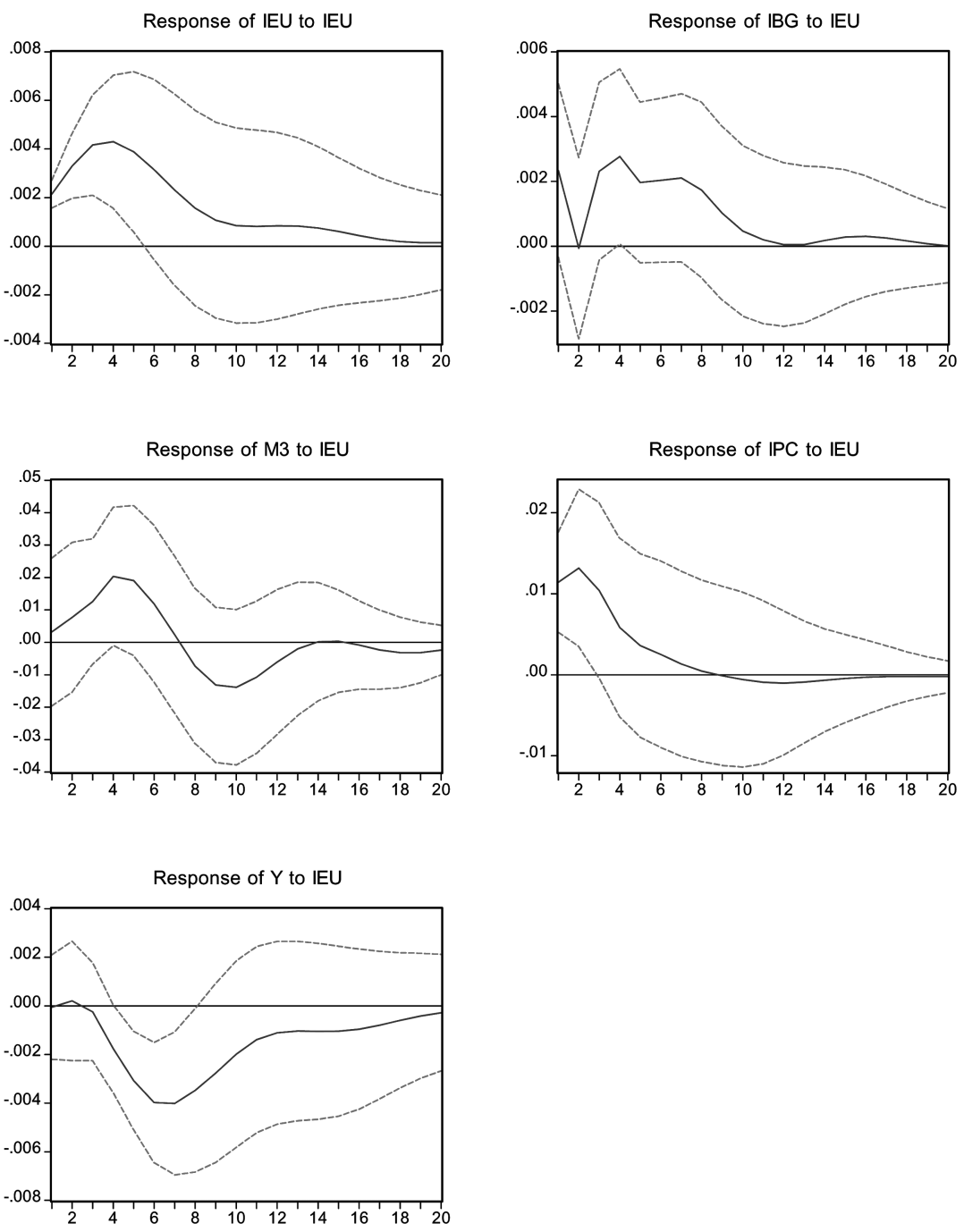

Note: The fact that IRFs to shocks stabilize and come back towards zero indicates on the one hand, that the SVAR model is correctly specified and, on the other, that all macroeconomic series are integrated of order zero. 
A.5: GIRFs in the Benchmark Model when Controlling for the Variation of Public Debt-toGDP Ratio

Response to Generalized One S.D. Innovations \pm 2 S.E.

Response of IEU to IEU

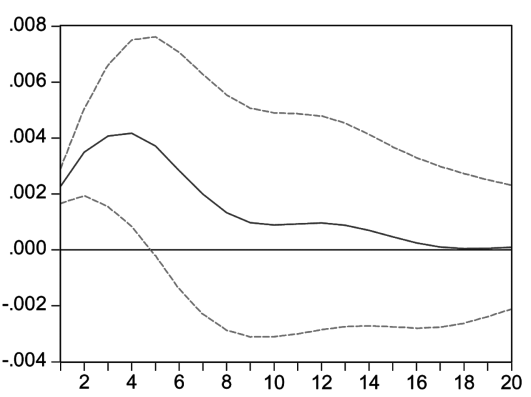

Response of $Y$ to IEU

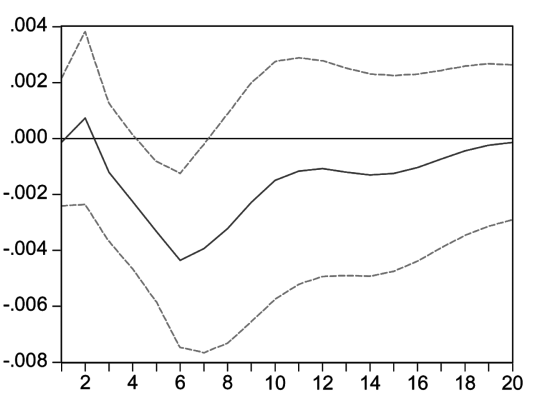

Response of M3 to IEU

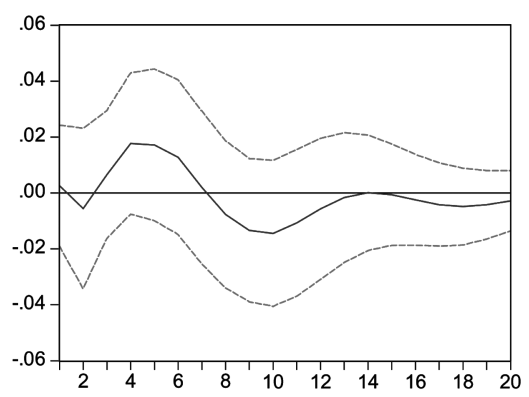

Response of IBG to IEU

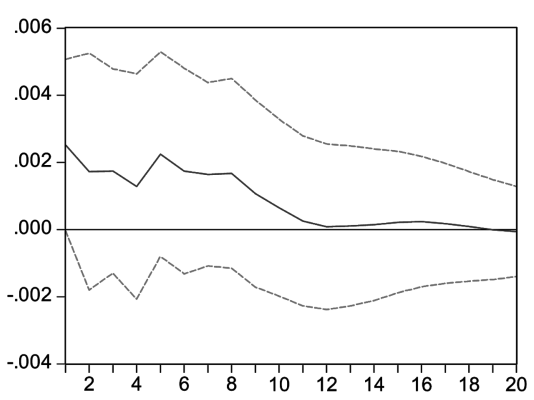

Response of IPC to IEU

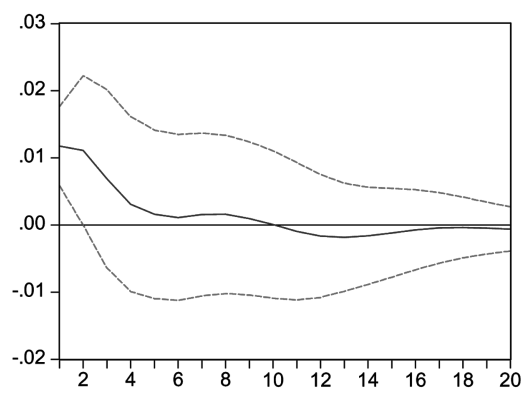


A.6: Reduction of the Size of the VAR by Restraining the Number of Variables The first four-variables VAR $\left(i^{E U}, i^{B G}, Y, I P C\right)$

Response to Generalized One S.D. Innovations \pm 2 S.E.

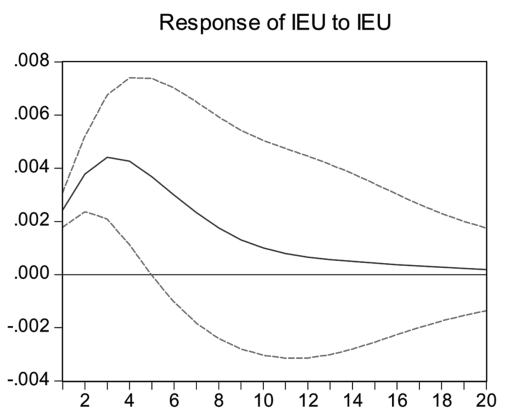

Response of IBG to IEU
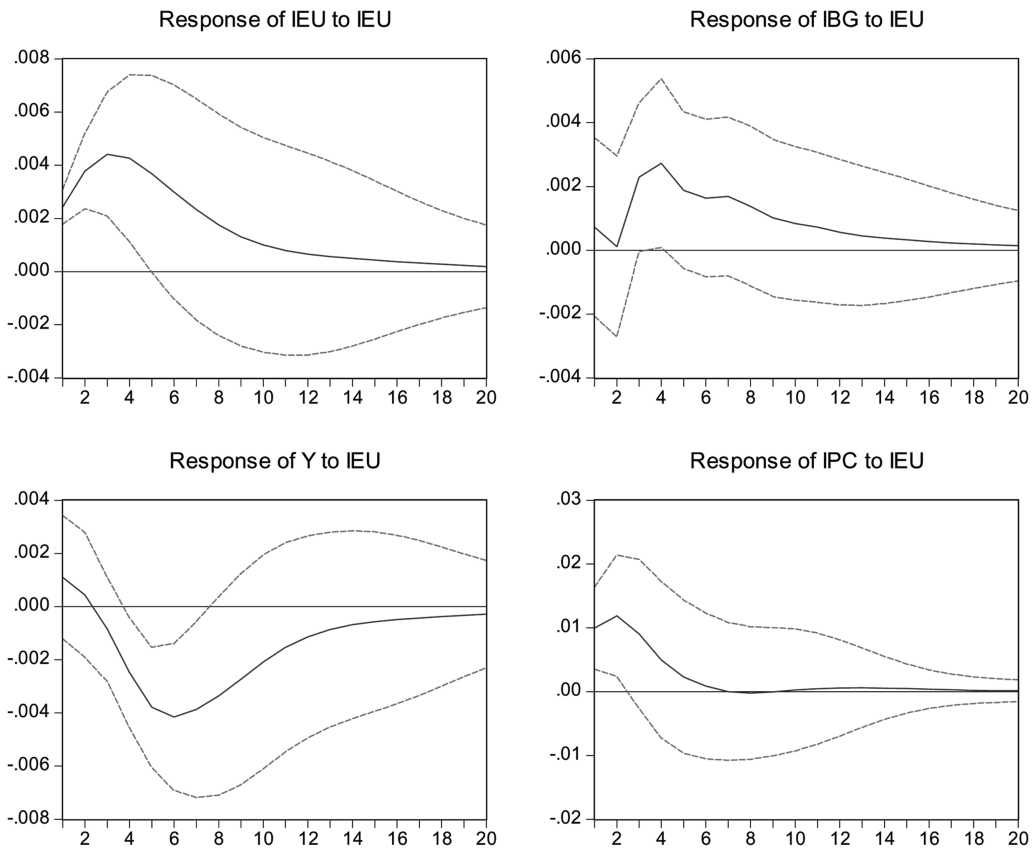

The second four-variables VAR $\left(i^{E U}, Y, I P C, M 3\right)$

Response to Generalized One S.D. Innovations \pm 2 S.E.

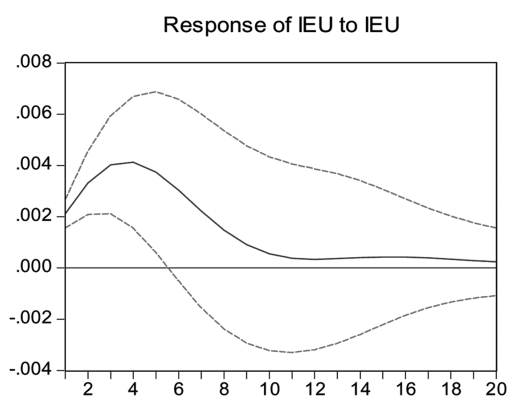

Response of $Y$ to IEU
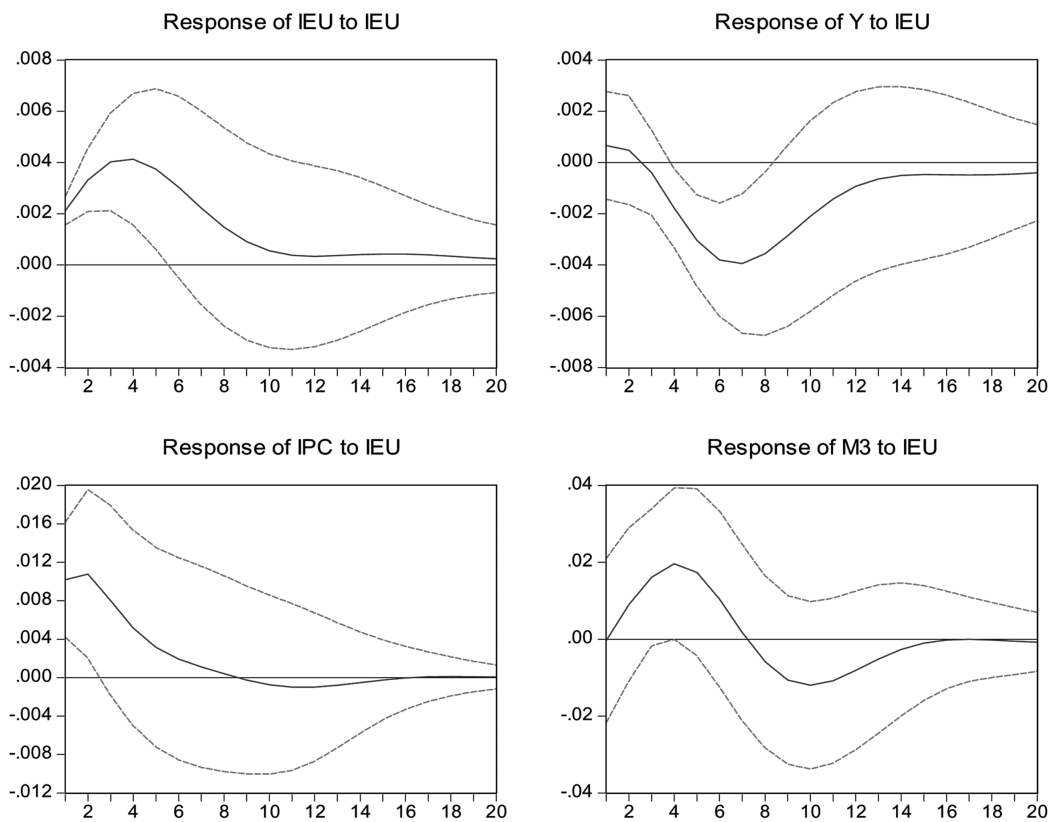


\section{References}

Babich, V.(2001), "Monetary Transmission in Latvia", Baltic Economic Trends, 2, pp.1627.

Bems, R.(2001), “The Monetary Transmission Mechanisms in the Baltic States: Introduction", Baltic Economic Trends, 2, pp.3-6.

Berlemann, M., Nenovsky, N.(2004), "Lending of First Versus Lending of Last Resort: the Bulgarian Financial Crisis of 1996/1997", Comparative Economic Studies, 46, pp.245-71.

Bernanke, B., Mihov, I.(1998), "Measuring Monetary Policy", Quarterly Journal of Economics, 113, pp.869-902.

Blanchard, O., Perotti, R.(2002), "An Empirical Characterization of the Dynamic Effects of Changes in Government Spending and Taxes on Output", Quarterly Journal of Economics, 117, pp.1329-68.

Blessing, J.(2007), "The Bulgarian Economy on its Way to the EMU: Economic Policy Results from a Small-Scale DSGE Framework", BNB Working Paper, No. 60.

Carlson, J., Valev, N.(2001), "Credibility of the New Monetary Regime: the Currency Board in Bulgaria", Journal of Monetary Economics, 47, pp.581-94.

Carrion-i-Silvestre, J., Sanso, A.(2006), "A Guide to the Computation of Stationarity Tests", Empirical Economics, 31, pp.433-48.

Christiano, L., Eichenbaum, M., Evans, C.(2000), "Monetary Policy Shocks: What have We Learned and to What End?", in Taylor, J., Woodford, M.(eds), Handbook of Macroeconomics, North-Holland, Amsterdam.

Coricelli, F., Egert, B., MacDonald, R.(2006), "Monetary Transmission in Central and Eastern Europe: Gliding on a Wind of Change", Focus on European Economic Integration, 1, pp.44-87.

Crowder, W., Wohar, M.(2003), "A Cointegrated Structural VAR Model of the Canadian Economy", Bank of Canada Working Paper.

Desquilbet, J.-B., Nenovsky, N.(2003), "Exploring the Currency Board Mechanism: a Basic Formal Model", BNB Working Paper, No. 35.

Desquilbet, J.-B., Nenovsky, N.(2004), "Credibility and Adjustment: Gold Standards Versus Currency Boards", BNB Working Paper, No. 39.

EFN (European Forecasting Network)(2004), "The Euro Area and the Acceding Countries", Annex 4, Reports, Spring.

Hanke, S.(2002), "On Dollarization and Currency Boards: Error and Deception”, Policy Reform, 5, pp.203-22.

Hanke, S.(2007), "Scorecard for Bulgaria's Currency Board", Central Banking, 18, pp.7577.

Hanke, S., Sekerke, M.(2003), "How Bulgaria is Destroying its 'Currency Board", Central Banking, 14, pp.81-84.

Hanke, S., Schuler, K.(1991), “Teeth for the Bulgarian Lev: a Currency Board Solution”, 
Washington, DC: International Freedom Foundation.

Hanke, S., Schuler, K.(1994), Currency Boards for Developing Countries: a Handbook, ICS Press, San Francisco, California.

Ho, C.(2002), "A Survey on the Institutional and Operational Aspects of Modern-Day Currency Boards", BIS Working Paper, No. 110.

Kwiatkowski, D., Phillips, P., Shin Y.(1992), "Testing for the Null Hypothesis of Stationarity against the Alternative of a Unit Root", Journal of Econometrics, 54, pp.159-78.

Lättemäe, R.(2003), "EMU Accession Issues in Baltic Countries", Ezoneplus Working Paper, No. 17A.

Lättemäe, R., Pikkani, R.(2001), "The Monetary Transmission Mechanism in Estonia", Baltic Economic Trends, 2, pp.7-15.

Lavrac, V.(2004), "Fulfillment of Maastricht Convergence Criteria and the Acceding Countries", Ezoneplus Working Paper, No. 21.

Leybourne S., McCabe, B.(1999), "Modified Stationarity Tests with Data-dependent Model Selection Rules", Journal of Business and Economic Statistics, 17, pp.264-70.

L'Horty, Y., Rault, C.(2004), "Inflation, Minimum Wage and Other Wages: an Econometric Study of French Macroeconomic Data", Applied Economics, 36, pp.277-90.

Lütkepohl, H.(1991), Introduction to Multiple Time Series Analysis, Springer-Verlag, Berlin.

Miller, J.(1999), "The Currency Board in Bulgaria: the First Two Years", BNB Working Paper, No. 11.

Mojon, B., Smets, F., Vermeulen, P.(2002), "Investment and Monetary Policy in the Euro Area", Journal of Banking and Finance, 26, pp.2111-29.

Nenovsky, N., Hristov, K.(2002), "The New Currency Boards and Discretion: Empirical Evidence from Bulgaria", Economic Systems, 26, pp.55-72.

Nenovsky, N., Hristov, K., Mihaylov, M.(2001), "A Simple Test of Currency Board Automatic Mechanism in Bulgaria, Estonia and Lithuania", Journal des Economistes et des Etudes Humaines, 11, pp.575-616.

Nenovsky, N., Rizopoulos(2004), "Extreme Monetary Regimes. Evidence from Currency Board Introduction in Bulgaria", Journal of Economic Issues, 37, pp.909-41.

Nenovsky, N., Chobanov, P., Mihaylova, G., Koleva, D.(2008), "Efficiency of the Bulgaria Banking System: Traditional Approach and Data Envelopment Analysis", AEAF Working Paper, No. 1/2008.

Ng, S., Perron, P.(2001), "Lag Length Selection and the Construction of Unit Root Tests with Good Size and Power", Econometrica, 69, pp.1519-54.

Niggle, C.(1991), "The Endogenous Money Supply Theory: an Institutionalist Appraisal", Journal of Economic Issues, 25, pp.137-51.

Orlowski, L.(2000), "Monetary Policy Regimes and Real Exchange Rates in Central Europe's Transition Economies", Economics Systems, 24, pp.145-66.

Peersman, G., Smets, F.(2001), "The Monetary Transmission Mechanism in the Euro 
Area: More Evidence from VAR Analysis", ECB Working Paper, No. 91.

Peersman, G., Straub, R.(2004), "Technology Shocks and Robust Sign Restrictions in an Euro Area SVAR", ECB Working Paper, No. 373.

Pesaran, H., Shin, Y.(1998), "Generalized Impulse Response Analysis in Linear Multivariate Models", Economics Letters, 58, pp.17-29.

Pikkani, R.(2000), "The Monetary Sector Under a Currency Board Arrangement: Specification and Estimation of a Model with Estonian Data", Bank of Finland Working Paper, No. 10.

Quah, D., Vahey, S.(1995), “Measuring Core Inflation”, Economic Journal, 105, pp.113044.

Reynard, S.(2007), "Maintaining Low Inflation: Money, Interest Rates, and Policy Stance", Journal of Monetary Economics, 54, pp.1441-71.

Schuler, K.(1992), Currency Boards, Dissertation, George Mason University.

Sephton, P.(1995), "Response Surface Estimates of the KPSS Stationarity Test", Economics Letters, 47, pp.255-61.

Sims, C.(1980), "Macroeconomics and Reality", Econometrica, 48, pp.1-48.

Sims, C.(1992), "Interpreting the Macroeconomic Time Series Facts: The Effects of Monetary Policy", European Economic Review, 36, pp.975-1000.

Stock, J., Watson, M.(2001), "Vector Autoregressions", Journal of Economic Perspectives, 15, pp.101-15.

Sul, D., Phillips, P., Choi, C.(2005), "Prewhitening Bias in HAC Estimation", Oxford Bulletin of Economics and Statistics, 67, pp.517-46.

Taylor, J.(1995), "The Monetary Transmission Mechanism: an Empirical Framework", Journal of Economic Perspectives, 9, pp.11-26.

Vetlov, I.(2003), "Monetary Transmission Mechanism in Lithuania", Bank of Lithuania Manuscript. 